\title{
Microwave Treatment of Polyacrylonitrile Powder Method Development and Effects of Surface Modification Porosity for Supercapacitor Devices or other Mobile Applications
}

\author{
Spiridon Koutsonas ${ }^{1, a^{*}}$, Geoffrey R. Mitchell ${ }^{2, b}$, Fred J. Davis ${ }^{3, c}$ \\ 1*Ulster University, Newtownabbey, BT37 0QB, Room 6C10, \\ NIACE Centre $1^{\text {st }}$ Floor, Airport Road, BT3 9DZ, Belfast, UK.
}

${ }^{2}$ Centre for Rapid and Sustainable Product Development, Institute Polytechnic of Leiria

Rua de Portugal, 2430-028 Marinha Grande, Portugal.

\author{
${ }^{3}$ School of Chemistry, Food and Pharmacy, University of Reading, Whiteknights, PO Box 226, \\ Reading RG6 6AP, Reading, UK. \\ a*s.koutsonas@ulster.ac.uk, ${ }^{b}$ geoffrey.mitchell@ipleiria.pt, cf.j.davis@reading.ac.uk
}

Keywords: Polyacrylonitrile, powder, degradation, microwave irradiation, supercapacitors

\begin{abstract}
The aim of this article is to develop a method in order to investigate the surface modifications of degraded polyacrylonitrile powders under microwave treatment in air. Microwave treatment of polyacrylonitrile powders in air recorded two stages of degradation firstly an exothermic reaction that started in the range of $(86-117)^{\circ} \mathrm{C}$. Secondly the Thermal runway here the weight loss reached a peak value between 80-90 percent with the small quantity of $0.25 \mathrm{~g}$ polyacrylonitrile and in the ashes with a bigger quantity $1 \mathrm{~g}$ of polyacrylonitrile. Scanning electron microscopy analysis technique revealed the morphological characteristics and the porosity of the carbon compound that may play an important role in the construction of high porosity area and so in electrochemical supercapacitor devices with high performances.
\end{abstract}

\section{Introduction}

Electrochemical engineering of nanoporous materials is a cost-effective synthesis approach that enables the production of a range of nanoscale materials with controllable dimensions and properties. Recent decades have witnessed extensive research activity into the advanced engineering of nanoporous materials, from fundamental studies to applied science. These nanomaterials offer a set of unique and exclusive advantages for a wealth of applications, including supercapacitors, fuel cells, batteries, catalysis, and harvesting, electronics, photonics, sensing, templates, and membranes. Degradation refers to the irreversible process by which an organic precursor deteriorates due to different external factors such as thermal, mechanical, light, or microwave treatment. The result of degradation is a carbon material with an increased high surface area. Production of increased specific surface area by degradation of carbon nanoporous materials has been discussed in a number of scientific papers $[1,2]$. We focus here on the potential of microwave treatment to produce such materialas in a sustainable manner using polyacrylonitrile (PAN) powders

\section{Background}

Degradation of carbon black (CB) based nanoporous materials can be used in the construction of electrochemical supercapacitors, fuel cells and in polymer batteries. The inclusion of high surface area nanoporous materials in conventional parallel plate capacitors can increase their capacitance some 10,000 times per $\mathrm{cm}^{2}$ compared to capacitors with ordinary dielectric materials [3]. This is a defining property of "supercapacitors". A supercapacitor is formed from two high surface area electrodes and an electrolyte interposed between them. The electrical charges are stored at the electrode/electrolyte interface area in a physical way and without chemical reactions. As the physical process of charge/discharge produces low amount of electric charges at the interfaces, a 
material of high surface such as PAN favours the storage of high energy and power density. In other words large specific-area porous electrodes can be an important factor to an increased capacitance. The very large, electrochemically accessible interfacial area should be permeated by an electrolyte in a small volume or small mass of the order of $\mathrm{cm}^{-3}$ or $\mathrm{g}^{-1}$. For example carbons having area $1000 \mathrm{~m}^{2} / \mathrm{g}$ of material exhibit $15 \mu \mathrm{F} / \mathrm{cm}^{2}$ of double-layer capacitance in some suitable electrolyte solution. Carbon powders that have been rubbed, crushed or worn down to micrometre dimensions can achieve high surface area as reported by Frackowiak, and Beguin [3] on their research paper.

The surface conditioning of powder carbon materials for supercapacitor fabrication is of substantial importance as is their conductivity and minimum self-discharge rates. Activated carbons utilise a complex porous structure composed of differently sized micropores, mesopores, and macropores to achieve an overall high surface area. Although capacitance is directly proportional to the surface area, empirical evidence suggests that not all the high surface area, contributes to the capacitance of the supercapacitor devices. It has also been demonstrated that there exists an empirical relationship between the distribution of the pores sizes, and the energy density stored in a device. A larger pore size correlates to higher energy density. Therefore the distribution of pore sizes of activated carbon materials is a major area of research in electrochemical supercapacitors. Researchers are now focusing on the determination of the optimal pore size and on improving the methods to control the pore size distribution during the fabrication [1, 4-9].

The microwave power absorption on the irradiated materials is predominantly affected by dielectric properties, which are changed by the material temperature. Since PAN powder absorbs microwave irradiation the application of microwave treatment could be a valuable and less expensive alternative to thermal treatment. Evidence of microwave treatment in PAN powders is scant in the research literature and this provides additional reasons to pursue such an investigation. Gasgnier et al [10], reported that a $\mathrm{CuO}_{2}$ and $\mathrm{C}$ mixture is heated by the $300 \mathrm{~W}$ of microwave power and the temperature in exceed of $130^{\circ} \mathrm{C}$, leading to an abrupt temperature rising. The abrupt rise in temperature by microwave irradiation is called thermal runaway (TR), and the temperature stating TR is designated as thermal runaway temperature TR. Therefore, it has been estimated that the TR is predominantly controlled by the dielectric loss of the irradiated material. The resultant TR should be a characteristic value for each material. The currently available microwave technology permits the development and implementation of a temperature programmed microwave assisted synthesis of ordered micro and mesoporous silica. Carbonisation of synthetic precursor such as polyacrylonitrile results in carbons with closed porosity. Activation of the chars requires very stringent conditions of temperature, time and environment. However, if carbonisation is carried out, ultimate char exhibits very high surface area and open accessible pores. In this case, normal pyrolysis takes place up to $700^{\circ} \mathrm{C}$ heat treatment. In excess $700^{\circ} \mathrm{C}$, starts PAN's activation reaction. Thus pyrolysis and activation can be performed on PAN precursors using $\mathrm{O}_{2}$ environment. Microwave heating of PAN at the temperatures of $\sim 300{ }^{\circ} \mathrm{C}$ and above causes a change in electrical properties from insulating to semiconducting as reported previously by Koutsonas [11], while heating PAN to temperatures in excess of $1000^{\circ} \mathrm{C}$ produces high strength carbon fibres.

The mechanism for PAN pyrolysis in an inert atmosphere is as follows: first, the nitrile group cyclise to form a ladder polymer; at higher temperatures, aromatisation takes place. At temperatures above $\sim 1000{ }^{\circ} \mathrm{C}$, all of the nitrogen and hydrogen have been eliminated to leave a graphitic structure. The mechanism suggests that, throughout the pyrolysis, the nitrogen present in the polymer is locked into six-member pyridinic rings. Pyrolysis of the PAN results in the formation of increasingly complex molecules containing nitrogen in pyridine like rings as reported by Weihua et al. [12]. 


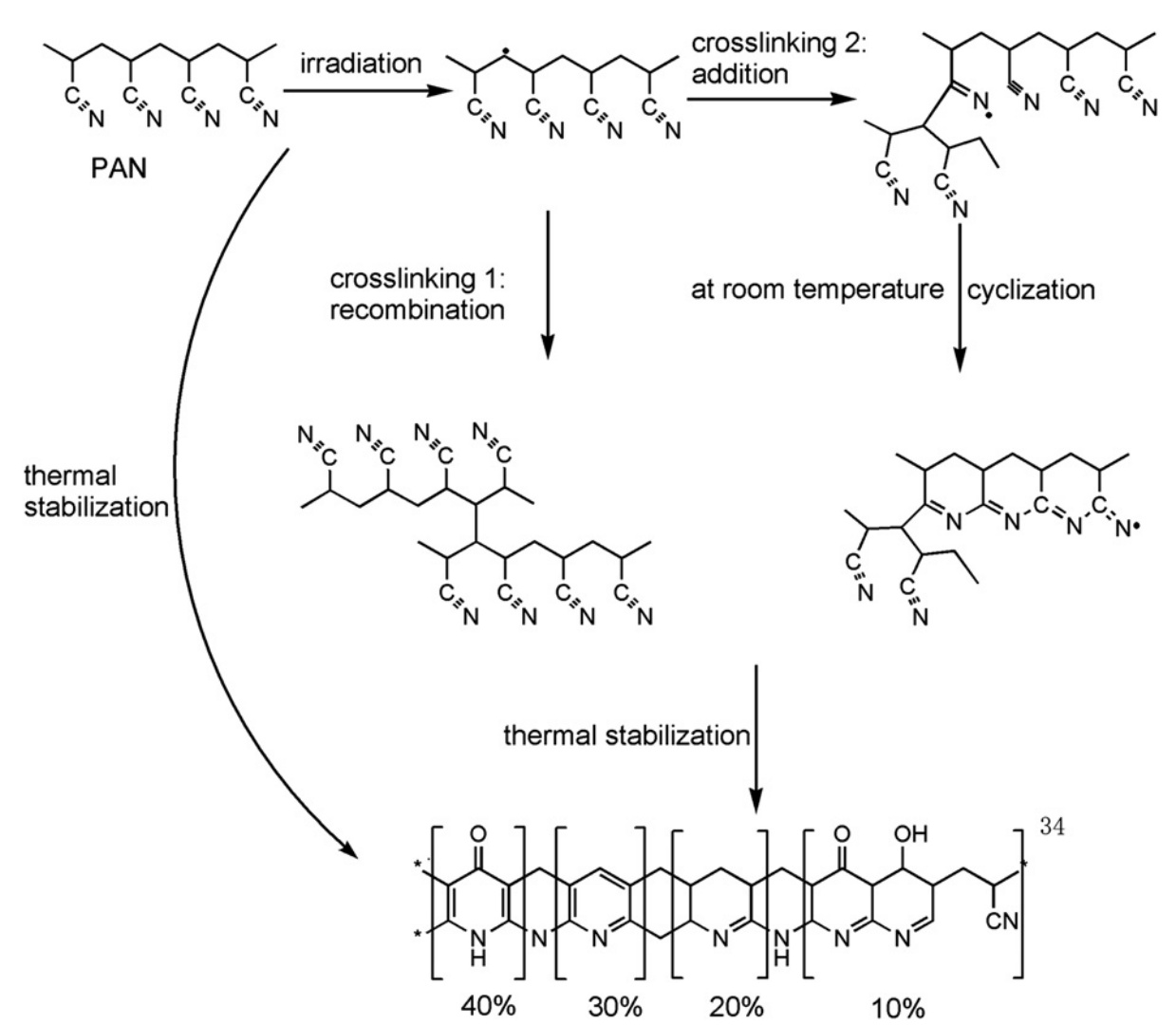

Figure 1: Possible mechanism for PAN degradation and reactions involved in the stabilization of PAN fibres, after Weihua et al. [12].

The molecular structure (Fig. 1) of degraded PAN gives a high axial compressive strength of PAN based carbon structures in comparison to pitch based carbon materials as reported by Weihua et al. [12]. The key to the microwave approach is the electronic conductivity of the PAN. No nanocarbons are obtained by using un-doped PAN. Alternatively electrically insulating PAN is used. The conductivity of conducting polymers such as PAN (between $10^{-1}-10^{2} \mathrm{~S} \mathrm{~cm}^{-1}$ ) is at an optimum range for microwave penetration into the bulk polymer. The conductivity is sufficiently high to absorb microwave radiation, but not so high to limit absorption to the surface. As long as the polymer remains conducting microwave absorption increases the temperature very rapidly resulting in loss of dopant ions and collapse of the polymer backbone to a carbon structure. Therefore it is very important for the PAN polymer not to de-dope too rapidly during the initial stages of microwave heating while the temperature is still relatively low. The microwave results in high temperature within a very short period of time (some hundreds seconds) [13-21].

Therefore microwave power absorption of the irradiated PAN material can affect its dielectric properties, static electrical conductivity as reported by Koutsonas [11] and possibly create a carbonised porosity with high surface area, which are collectively referred to as degradation of PAN and are important factors for materials in applications such as supercapacitors for mobile applications. If the variations in these properties can be detected after microwave treatment they can be indicative of the degree of degradation of the PAN [11].

\section{Description of the Experimental Set Up}

The material used for this investigation was a polyacrylonitrile powder (Sigma-Aldrich) density $1184 \mathrm{Kg} / \mathrm{m}^{3}$, refractive index $\mathrm{n}=1.514$, transition temperature $\mathrm{T}_{\mathrm{m}}=317^{\circ} \mathrm{C}$, with an average molecular weight $\mathrm{M}_{\mathrm{w}}=150,000$. A microwave oven (CEM Discovery) was used in this work with a maximum temperature of $300^{\circ} \mathrm{C}$ with 300 Watt of power shown in Figure 2.

Samples of PAN powder were used in four different quantities of approximately $0.25 \mathrm{~g}, 0.5 \mathrm{~g}, 0.75$ $\mathrm{g}$, and $1 \mathrm{~g}$ were tested each time. 


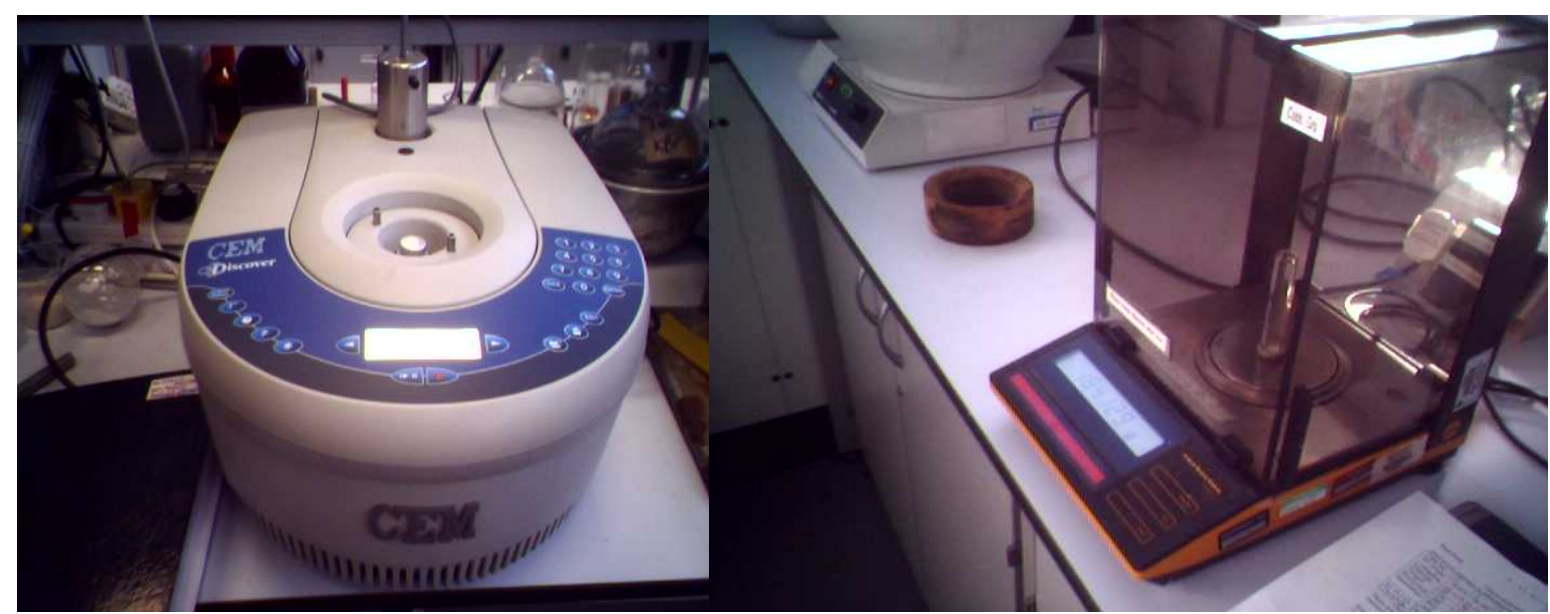

Figure 2: Photograph of the CEM Discover microwave oven with the microwave cavity leakage protection on top centre of the apparatus used .

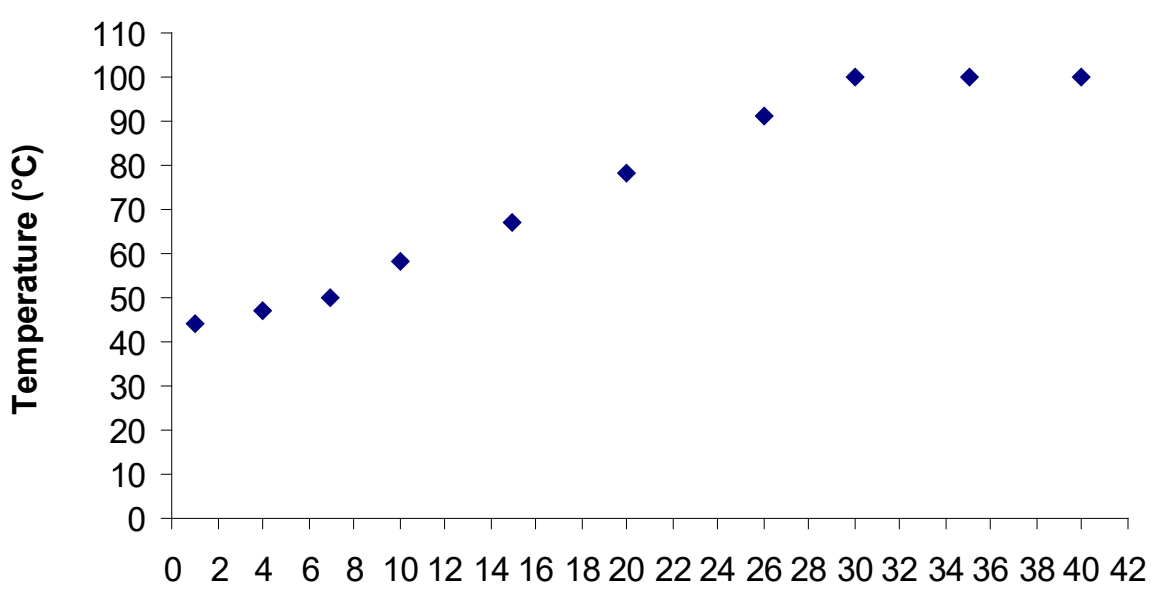

Time (s)

Figure 3: A plot of the recorded temperature of $1 \mathrm{~g}$ of distilled water placed in the microwave oven after application of the microwave power.

Fiqure 3 shows the rise in temperature measured with a digital thermometer with time for $1 \mathrm{~g}$ of distilled water placed in a glass vial in the microwave apparatus. Time zero corresponds to the application of the microwave power. The microwave oven was set with a power of $300 \mathrm{~W}$. The measured temperature was calibrated at the boiling point for the distilled water. We can see from Figure 3 that it takes about 30 seconds to achieve the target temperature $100^{\circ} \mathrm{C}$. We repeated these measurements several times with similar results indicating that both the CEM apparatus and the digital temperature recorder yielded reproducible data.

\section{Results}

We now consider the effect of the microwave treatment on PAN powders in air. For the main part of the investigation different four quantities of PAN powder were weighed placed inside open glass vial. 
Table 1: The four quantities of PAN powder with the temperatures of exothermic reactions under microwave treatment in air.

\begin{tabular}{cccc}
\hline $\begin{array}{c}\text { Mass of PAN } \\
\text { powder }(\mathrm{g})\end{array}$ & $\begin{array}{c}\text { Exothermic } \\
\text { React. Start } \mathrm{T}\left({ }^{\circ} \mathrm{C}\right)\end{array}$ & $\begin{array}{c}\text { Final } \\
\text { Colour }\end{array}$ & $\begin{array}{c}\text { \% weight } \\
\text { loss }\end{array}$ \\
\hline 0.25 & 117 & Black & 4.5 \\
0.5 & 111 & Black & 5.6 \\
0.75 & 102 & Black & 8.8 \\
1 & 112 & Black & 10.1 \\
\hline
\end{tabular}

The polymer was treated in open air condition with the microwave oven preset with a power of $300 \mathrm{~W}$ for a runtime of 10 minutes. Figure 4 shows plots of the temperature for each sample mass as a function of time. We see that the thermal runaway was initiated a time in the range of 200-350 seconds of microwave treatment.

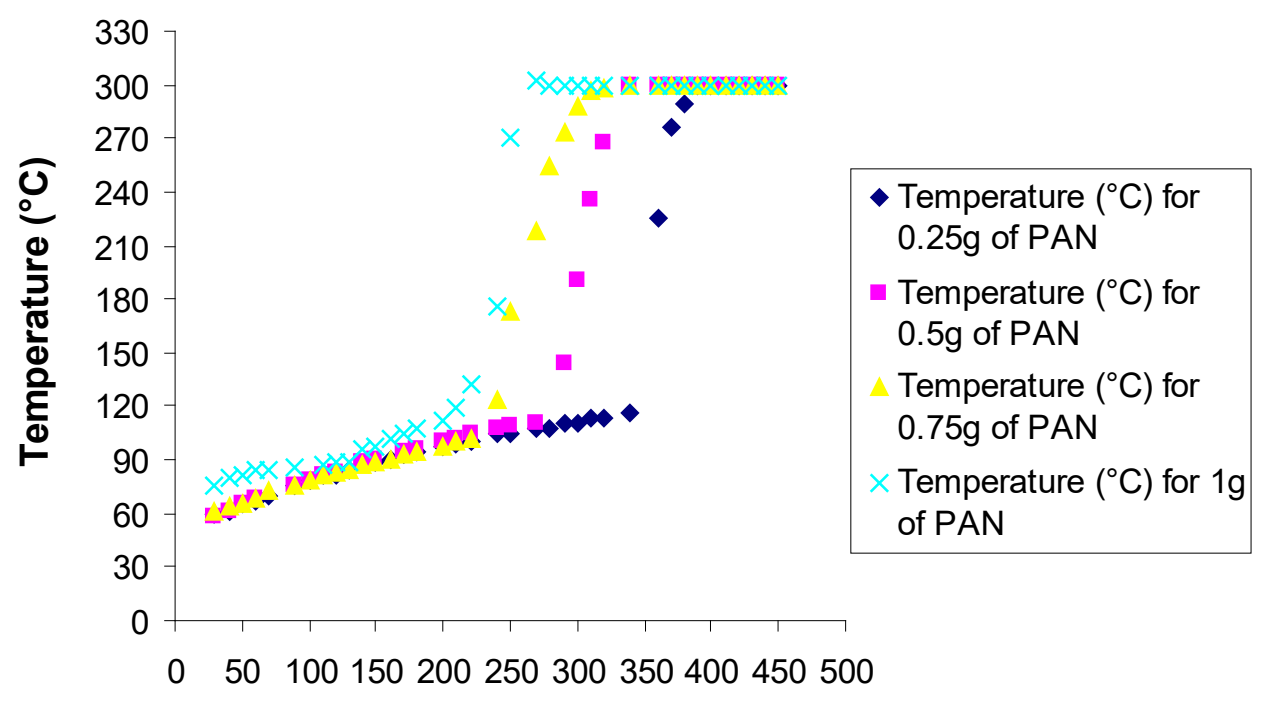

Time (s)

Figure 4: Plots of the temperature of the PAN powder sample as a function of time following the application of the microwave energy.

Figure 5 shows a plot of the temperature of initiation of the thermal runaway against the initial mass of the sample.

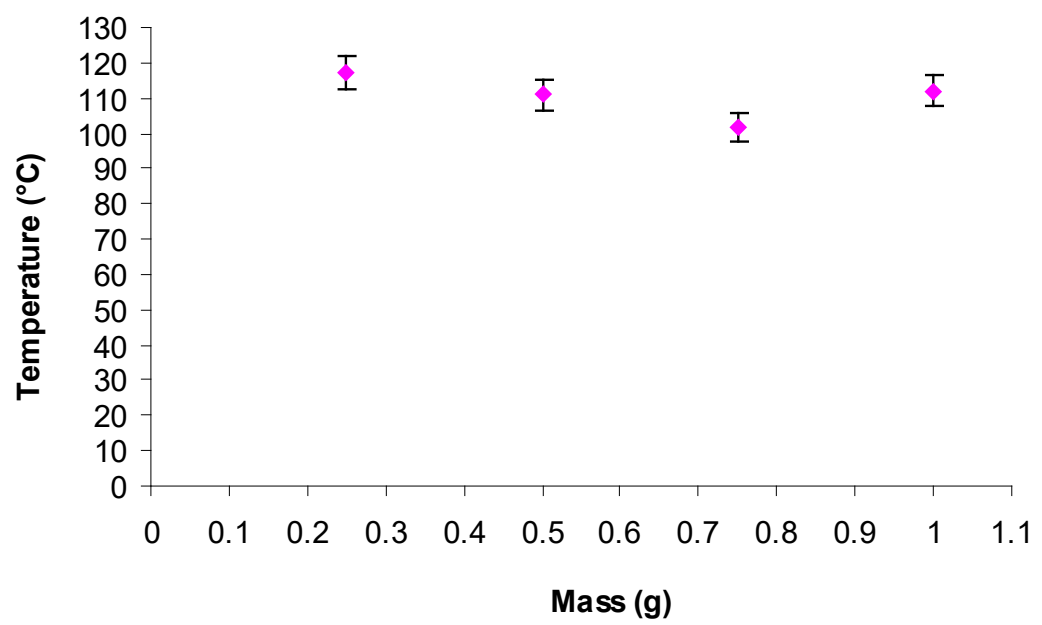

Figure 5: A plot of the temperatures which initiated the thermal run away as a function of the sample mass. 


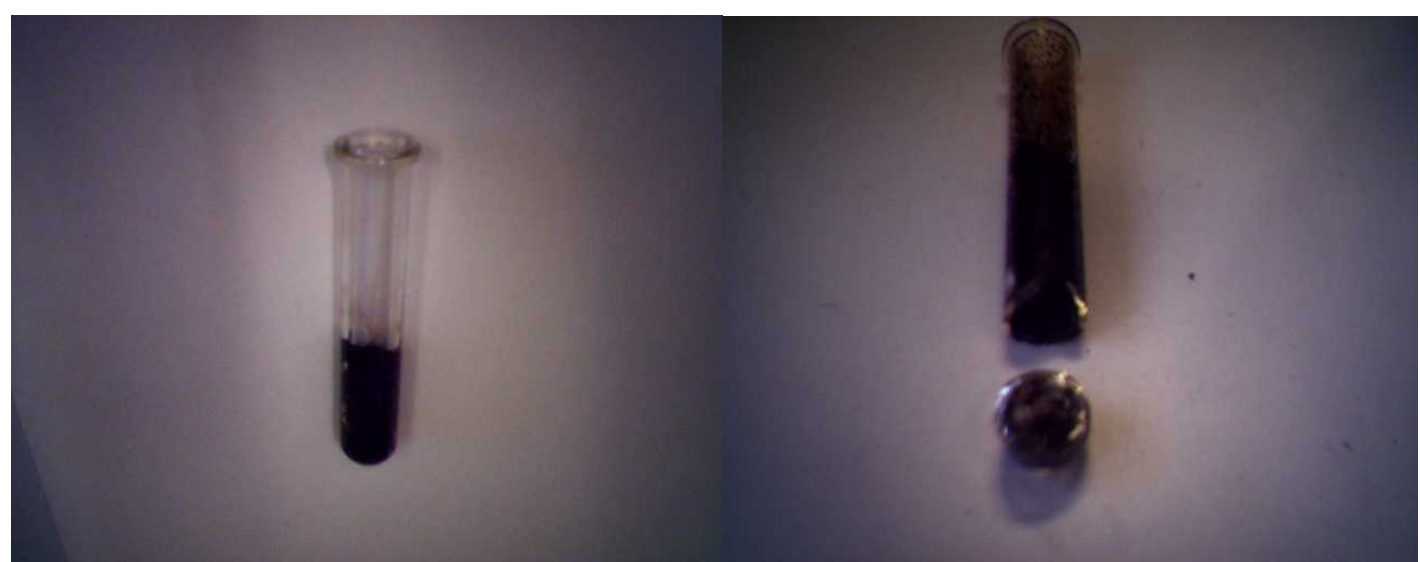

(a)

(b)

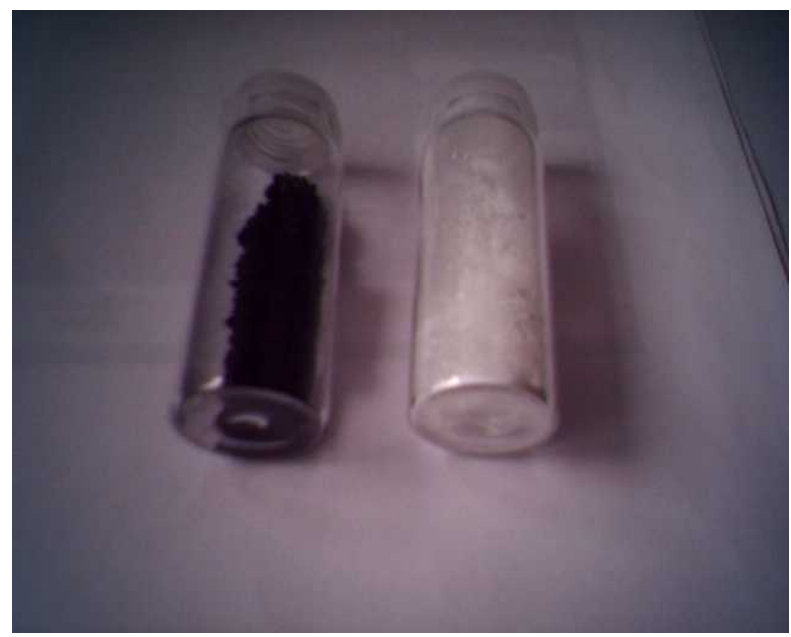

(c)

Figure 6: Photographs of the PAN powders after microwave treatment. (a) The vial glass (left) for $0.25 \mathrm{~g}$ of PAN after 4.5 hours of microwave treatment, (b) Sample after the thermal runaway for $1 \mathrm{~g}$ of PAN, (c) PAN powder (left) treated with microwaves for 4.5 hours, in air conditions and untreated white PAN powder (right).

Visual inspection of the treated powders can be informative on the results of the microwave treatment. Figure 6 shows selected images of processed powders.

The temperature of the exothermic reaction was determined each time from the instant at which the digital thermometer recorded a rapidly increasing temperature to the point where the microwave power was automatically cut off to $0 \mathrm{~W}$ to balance this temperature increase at $300^{\circ} \mathrm{C}$.

Figure 7 shows SEM micrographs obtained for the PAN powder and treatments described above. The surface area is full of irregularities and holes which indicates porosity. The overall surface at the two magnifications resembles that of "sponge" with rounded edges and relatively large cavities, indicating how microwave treatment in air affects the PAN surface area. Intuitively it becomes understood that a surface that is dense in small cavities and peaks should have an overall greater area than a surface which is smooth and deficient in cavities. 


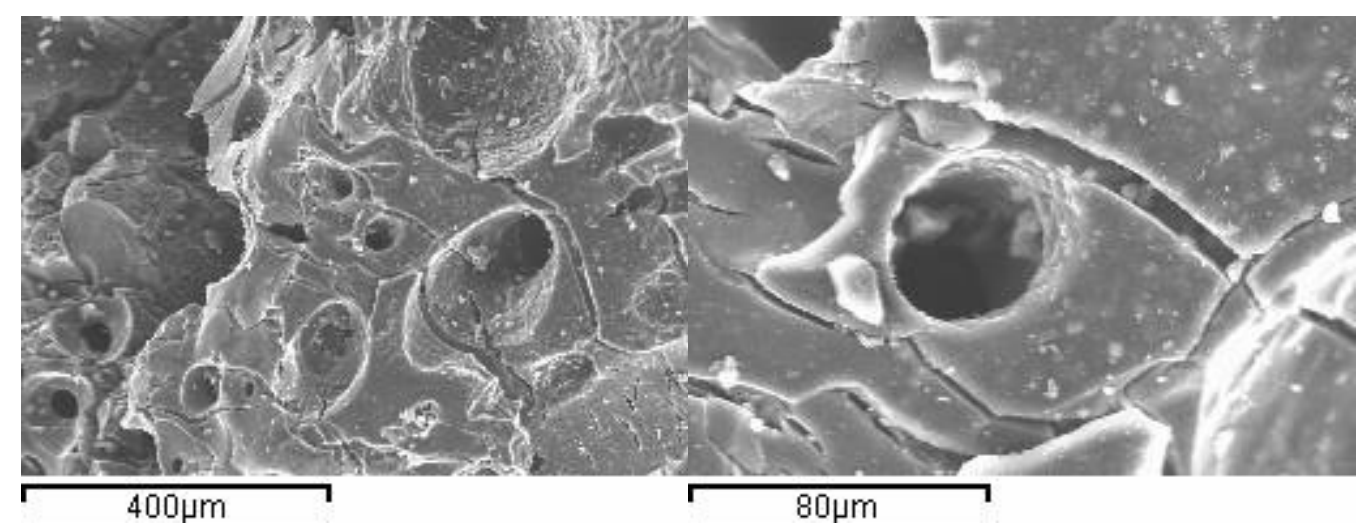

Figure 7: SEM image of PAN powder after microwave treatment in the air with CEM apparatus at $300 \mathrm{Watt}$, scale i) $400 \mu \mathrm{m}$, ii) $80 \mu \mathrm{m}$ at $20 \mathrm{kV}$.

The following general observations and results were recorded:

a) The exothermic reactions of all four samples took place in the range of $(102-117)^{\circ} \mathrm{C}$. The noticeable effect is that the temperature range of the exothermic reaction remained approximately constant as the initial mass increased, figure 5. During the reaction a weight loss was recorded.

The final product was a black, and presented in figure 6 . After the end of the exothermic reaction the final products had a reduced weight in the range of $4.5-10 \%$ of their initial weight (Table 1). The fractional weight loss of PAN powder increased as a function of the initial PAN quantity in the vial glass, as can be seen from Table 1:

b) $0.25 \mathrm{~g}$ sample of PAN powder was treated with the microwave apparatus for 4.5 hours at $300 \mathrm{~W}$. This led to the thermal run away effect, whereby the temperature of the sample increased very rapidly after 4.5 hours. At temperatures above $300^{\circ} \mathrm{C}$, black smoke came out of the sample and within a few seconds the vial glass melted and broke figure $6 \mathrm{~b}$. The rapid increase in temperature was followed by a rapid increase in the weight loss from a little less than $10 \%$ up to $20 \%$ of the initial quantity within $\sim 3.5-4$ seconds. The change in colour, which resulted from this treatment of the material, is shown in figure $6 \mathrm{c}$ ):

c) The effect of the thermal runaway was repeated with $1 \mathrm{~g}$ of PAN powder with the microwave system set at $300 \mathrm{~W}$ but with 1.5 hours of microwave treatment. Again the vial glass broke but this time only ashes could be observed. By matching to a colour char we identified the colour as, Dim Gray $^{6}$ [22]. This material was analysed with SEM analysis technique (Figure 7).

A question that arises is how much of it can be active in applications such as super-capacitors and also to pinpoint the treatment conditions that lead to a particular surface texture remain challenges for future work.

\section{Discussion}

The conventional thermal process, for PAN requires high temperature ovens under $\mathrm{N}_{2}$ or $\mathrm{H}_{2}$, which in turn requires a high cost. The microwave power absorption of the irradiated PAN material can be a valid alternative for the production of high surface area and so for a polymer supercapacitor device for mobile application as reported on the introduction part of this research paper. More important factors in the performance of applications such as supercapacitors are if the variations in porosity can be detected after microwave treatment they can be indicative of the degree of degradation of the PAN. For this purpose SEM analysis was used in order to identify the generation of the porosity after a specific microwave treatment. In this work differences in colour and percentage weight loss clearly indicated that under microwave irradiation the PAN powder reacted with a mechanism (of simple irradiation) as reported previously. This is a key point for further investigation and with other analysis techniques for the manufacturing of novel controlled porous PAN carbon based materials for electrochemical supercapacitor devices. Finally SEM analysis on 
carbonized monolithic PAN treated by microwaves at $300 \mathrm{~W}$ showed the presence of meso and microporosity. A more systematic study over greater number of specimens and conditions is necessary to pinpoint correlations between different ratio treatments and porosity related to surface morphology and these remains to be determined in future investigations.

\section{Summary}

PAN powders were treated with microwave radiation.

1) When the materials were treated in air, firstly an exothermic reaction was observed that started in the range of $(86-117)^{\circ} \mathrm{C}$. Two events were recorded in this regime: i) the material turned to black and ii) a weight loss was recorded. Both of these were indications of PAN degradation. Secondly the effect of thermal runaway was observed for $0.25 \mathrm{~g}$ of PAN after 4.5 hours, for $1 \mathrm{~g}$ of PAN after 1.5 hours of the same microwave treatment at $300 \mathrm{~W}$.

2) In each case the material reacted exothermally. The weight loss reached a peak value with the small quantity of $0.25 \mathrm{~g}$ PAN and in the ashes with a bigger quantity $1 \mathrm{~g}$ of PAN.

3) SEM analysis technique revealed the morphological characteristics and the porosity of the remaining carbon compound. Polyacrylonitrile surface modification may play an important role in the construction of high porosity area and so in electrochemical supercapacitor devices with high performances.

\section{Acknowledgment}

The work at CDRSP was supported by the FCT (Portugal) through Strategic Project - UI 4044.

\section{References}

[1] B.E.Conway Electrochemical Superconductors Scientific Fundamentals and Technological Applications (1999) Kluwer Academic/Plenum Publishers, New York ISBN 0-306-45736-9.

[2] B.E Conway in Proc. $34^{\text {th }}$ Intl. Power Sources Simposium, p.319, Catalog no.90CH 2866-9, Institute of Electrical and Electronics Engineers, New York (1990).

[3] E. Frackowiak, and F. Beguin (2001). "Carbon materials for the electrochemical storage of energy in capacitors." Carbon 39 (6): 937-950.

[4] S. Gottesfeld, in Proc. First Intl. Seminar on Double-Layer Capacitors and Similar Energy Storage Devices, S. P. Wolsky and Marincic, eds. Florida Educational Seminars, Boca Raton, Fla. (1991).

[5] S. Gottesfeld, A. Redondo, and S.W. Feldberg, Journal Electrochemical Society 134, 271 (1987).

[6] A. Rudge, I. Raistrick, S. Gottesfeld, and J.P.Ferraris Electrochemical Society 39, 273 (1994); and Electrochem. Acta, 39, 273 (1994).

[7] A. Rudge, J. Davey, I. Raistrick, and S. Gottesfeld, Journal of Power sources 47, 89 (1994).

[8] A. Rudge, J. Davey, F. Uribe, J. Landeros, and S. Gottesfeld, in Proc. Third Intl. Seminar on Double-Layer Capacitors and Similar Energy Storage Devices, S.P.Wolsky and N. Marincic, eds, Florida Educational Seminars, Boca Raton, Fla (1993).

[9] D. Finello, D. Harrison, and R. K. Bunting, in Proc. Second Intl. Seminar on Double-Layer Capacitors and Similar Energy Storage Devices, S.P. Wolsky and N. Marincic, eds, Florida Educational Seminars, Boca Raton, Fla (1992).

[10] M. Gasgnier, A. Petit, H. Jullien, A. Loupy, Materials Research Bulletin 31 (9) (1996) 11011109. https://doi.org/10.1016/0025-5408(96)00103-1. 
[11] S. Koutsonas "Electrical conductivity of degraded polyacrylonitrile powder by microwave irradiation for supercapacitor devices or other mobile applications", Materials Letters (Elsevier) Volume 193, 15 April 2017, Pages 203-205. http://dx.doi.org/10.1016/j.matlet.2017.02.001.

[12] L. Weihua, W. Mouhua, X. Zhe, Q. Yingna, W. Guozhong, Radiation-induced crosslinking of polyacrylonitrile fibers and the subsequent regulative effect on the preoxidation process, Radiation Physics and Chemistry 81 (2012) 622-627.

[13] R. Kotz and M. Carlen, Principles and applications of electrochemical capacitors. Electrochim Acta 45 15/16 (2000), pp. 2483-2498.

[14] P. Nikolaev, M.J. Bronikowski, R.K. Bradley, F. Rohmund, D.T. Colbert, K.A. Smith et al., Gas-phase catalytic growth of single-walled carbon nanotubes from carbon monoxide. Chem Phys Lett 313 1/2 (1999), pp. 91-97.

[15] M. Molina-Sabio, M.T. Gonzalez, F. Rodriguez-Reinoso and A. Sepulveda-Escribano, Effect of steam and carbon dioxide activation in the micropore size distribution of activated carbon. Carbon 344 (1996), pp. 505-509.

[16] A. Addoun, J. Dentzer and P. Ehrburger, Porosity of carbons obtained by chemical activation: effect of the nature of the alkaline carbonates. Carbon 407 (2002), pp. 1140-1143.

[17] B.E. Conway and W.G. Pell, Power limitations of supercapacitor and capacitance distribution operation associated with resistance in porous electrode devices. J. Power Sources 1052 (2002), pp. $169-181$.

[18] C. Zhou, T. Liu, T. Wang, S. Kumar PAN/SAN/SWNT ternary composite: Pore size control and electrochemical supercapacitor behaviour. Polymer 47 (2006) pp.5831e5837

[19] X. Zhang and S. K. Manohar, "Microwave synthesis of nanocarbons from conducting polymers", Chemical Communications (23): 2477-2479 2006.

[20] K.F. Czaplewski, T.L. Reitz, Y-J Kim, R.Q. Snurr RQ Mircroporous and Mesoporous Materials 2002, 56:55; McMillan SA, Broadbelt LJ, Snurr RQ Journal of Phys. Chem. B 2002, 106: 10864.

[21] R. Poladi, H. P. R.; Landry, C. C. "Oxidation of Octane and Cyclohexane Using a New Porous Substrate, Ti-MMM-1," Microporous Mesoporous Mater. 2002, 52, 11.

[22] http://www.1954advance-design.com/AdvanceDesignTrucks/1954ColorsStripes.htm (Last assessed 11.12.2017). 